\section{Tables of letter sequences varying in order of approximation to English*}

\author{
KENICHI HIRATA and M. P. BRYDEN \\ University of Waterloo, Waterloo, Ont., Canada
}

To obtain more complete tables of letter sequences varying in order of approximation to English than those generally available, sequences of zero through fourth-order approximation were computer-generated using tables of single-letter, digram, trigram, and tetragram frequencies. Two sets of tables are presented. One consists of 100 randomly selected 10 -letter sequences of each of zero to fourth-order material. The other consists of 408 -letter sequences of each type, selected with the restriction that no letter appear more than once in the sequence.

In attempts to manipulate familiarity while controlling meaningfulness, many studies of shortand long-term memory and of tachistoscopic word recognition have employed stimuli differing in order of approximation to English (e.g., Baddeley, 1964; Mewhort, 1967; Mewhort, Merikle, \& Bryden, 1969; Merikle, 1969; Miller, Bruner, \& Postman, 1954). Different orders of approximation to English reflect various degrees of sequential dependencies of English with higher-order approximations more closely resembling ordinary English.

The concept of orders of approximation to English dates back to Shannon's (1948) original work in the field of information theory. A zero-order approximation to Enligsh is simply a string of letters selected at random, while a first-order approximation takes into account the relative frequency of the single letters of the alphabet. In a second-order approximation, each pair of letters is selected in such a way as to reflect the digram frequencies of English, and so on. In general, it is possible to construct sequences of nth order approximation to English, given the relative frequencies of the $n$-grams in English.

In practice, several different methods have been used to obtain orders of approximation to English. Miller \& Selfridge (1950) and Shannon

*This work was supported by Grant No. A-95 from the National Research Council of Canada to the second author. The authors are indebted to Douglas Mewhort and Philip Merikle for their encouragement and advice.
(1951) employed a guessing technique that takes advantage of the normal adult's familiarity with English letter sequences. Here, a person would be shown a sequence of letters and asked to construct a word using the sequence of letters. The first letter he added to the string would be incorporated into it, the original first letter dropped and the new string passed on to another individual. While this is an interesting and often entertaining classroom demonstration, college students misjudge the relative frequencies of individual letters (Attneave, 1953), not to mention digram or polygram frequencies.

Miller, Bruner, \& Postman (1954) followed a basically similar procedure, but used text material rather than people to generate their material. Their procedure required a rather laborious search of text material for the recurrence of particular strings of letters. An alternative method would be to make use of a complete table of the frequencies of n-grams of a given order.

The most complete available tables of different orders of approximation are those of Miller, Bruner, \& Postman (1954). They provide 15 eight-letter sequences of zero-, first-, second-, and fourth-order approximation. Since many experiments require longer of a given order of approximation, it seemed worthwhile to attempt to generate such material.

In constructing our orders of approximation, we made use of the tables of single-letter, digram, trigram, and tetragram frequencies published by Mayzner \& Tresselt (1965) and sequences. or more than 15 examples
Mayzner, Tresselt, \& Wolin (1965a, b). Our procedure is best illustrated by an example of how a third-order approximation was constructed. Given an initial digram, let us say ST, all trigrams commencing with ST were weighted by assigning them a set of numbers proportional to their relative frequency. A random number was then drawn to indicate which letter should be added to our sequence. Suppose this letter were E: we would then add $E$ to our sequence to make STE and repeat the procedure with trigrams commencing with TE. This procedure was carried out iteratively until it reached a point where all trigrams commencing with the desired digram had observed frequencies of zero. The resulting strings of letters, making use as they do of observed polygram frequencies, should be limited only by the accuracy of the original frequency counts.

To obtain the desired letter sequences, we generated 10,000 letters at each order of approximation. For zero, first, and second orders, this produced a single long string that could be sampled at random. With higher orders of approximation, the fact that particular sets of trigrams or tetragrams had observed frequencies of zero resulted in periodic termination of the string. In such cases, we simply started at a different point and began another string.

For experimental use, we have presented two sets of tables. In the first set, Tables 1-5, there are 100 10-letter sequences of each of zerothrough fourth-order material. These have been selected randomly from our computer printout, subject to the limitation that the sequence had to be at least 10 letters in length, and very obvious words or phrases (e.g., AVOICECAME) have been eliminated. Shorter sequences may be constructed by deleting letters from either or both the end and the beginning.

Many Es are also interested in serial position effects, and these are difficult to assess when individual letters are repeated within a sequence. For this reason, we have also selected sequences varying in order of approximation that have no repeated letters. Table 6 gives 40 examples of eight-letter sequences of each order of approximation that have no repeated letters. 


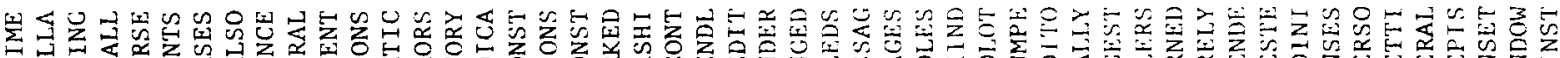

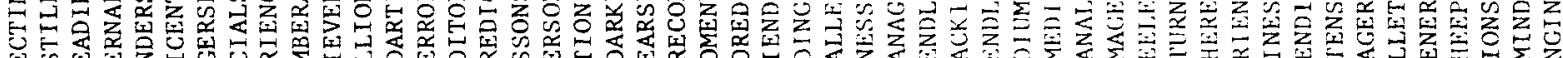

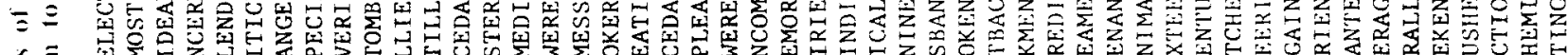

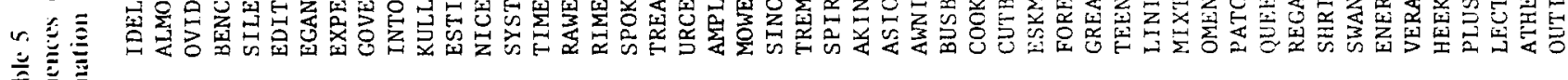

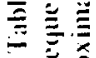

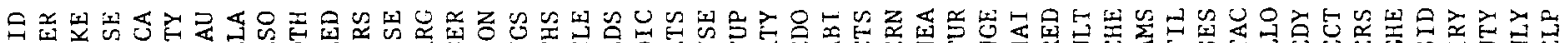

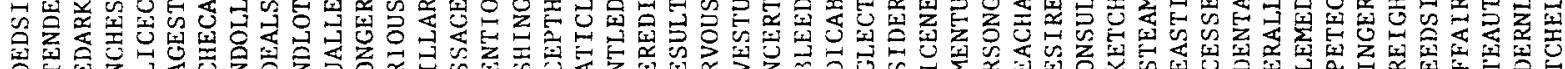

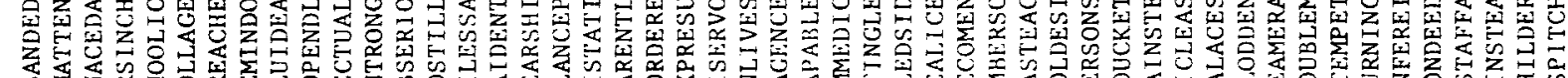

产紊

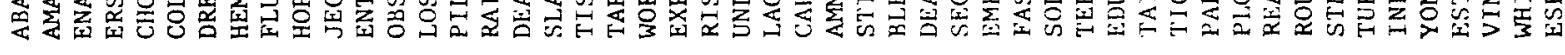

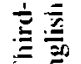

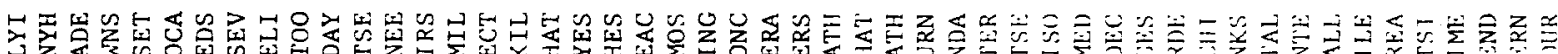

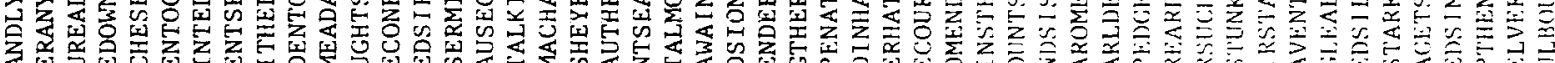

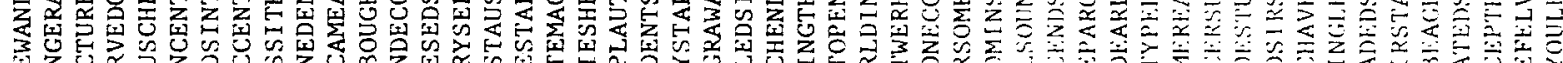

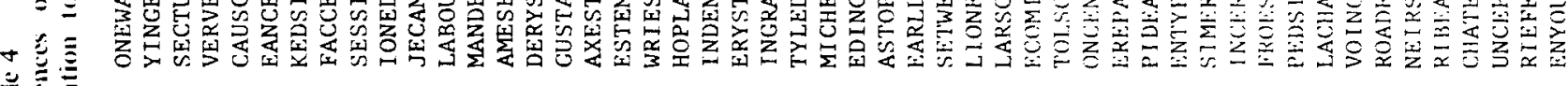

要要

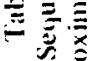

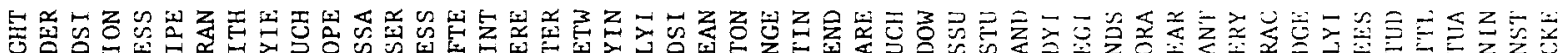

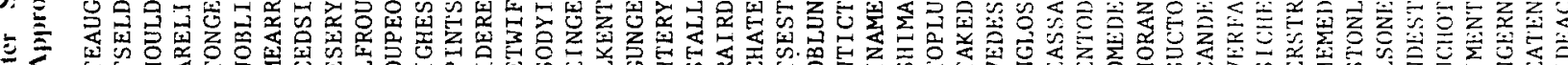

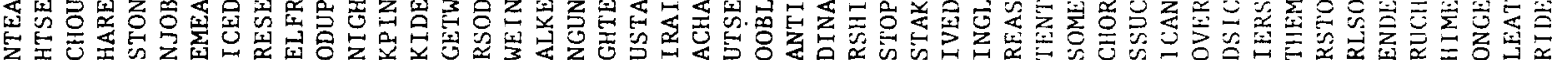

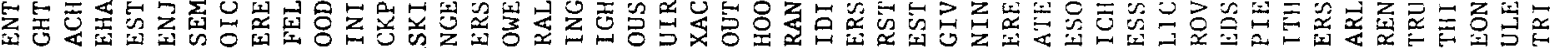
三菖

言

象

$\bar{\Xi}$

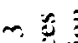

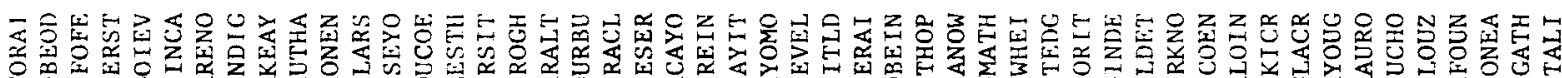

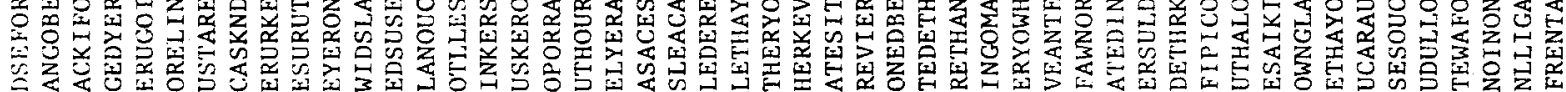

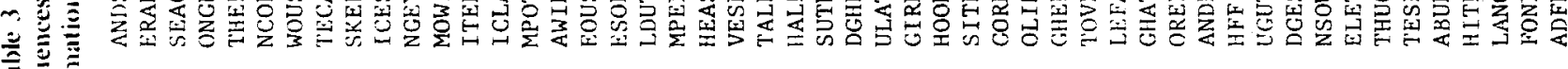

$=\frac{\bar{x}}{2} \cdot \frac{1}{x}$

产

妾

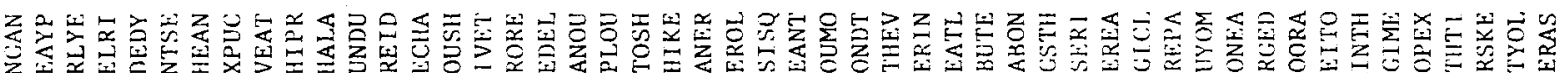

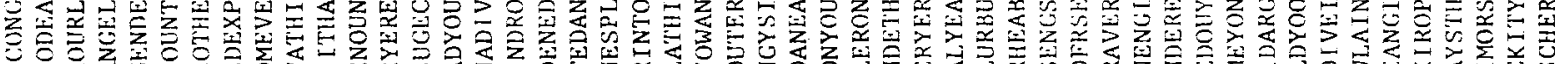

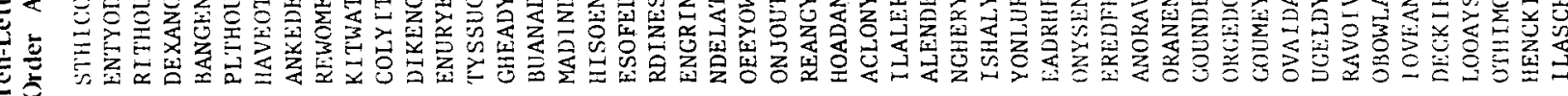

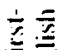

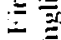

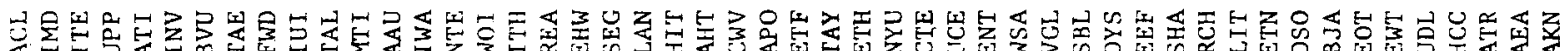

$\bar{\Xi} \bar{\Xi}$

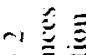

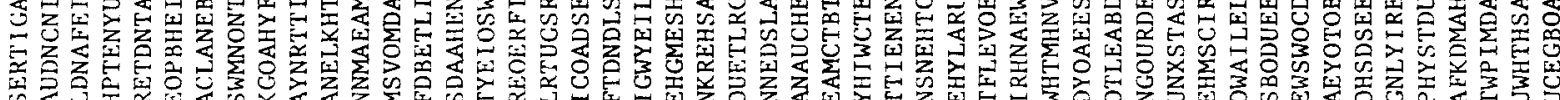

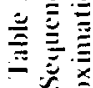

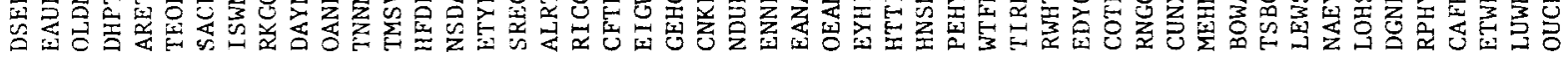

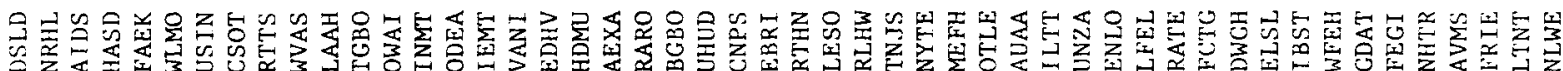

岁竞

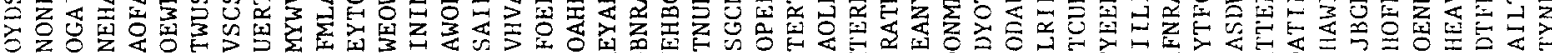

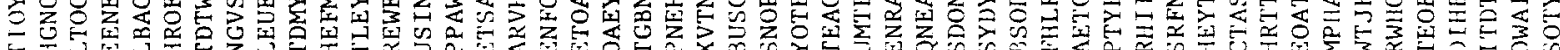

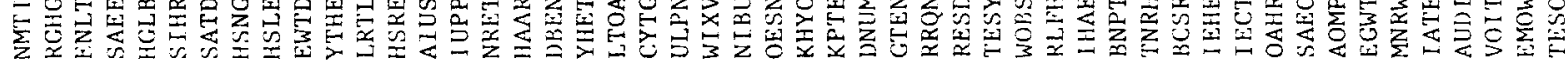

$\equiv \overline{\overline{\underline{x}}}$

$\stackrel{i}{*}$

$\bar{\Xi}$

-

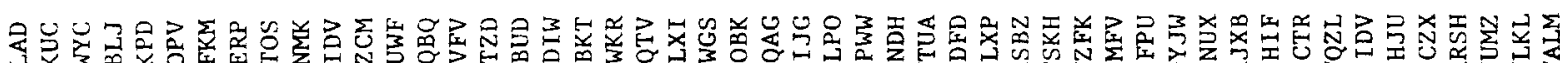

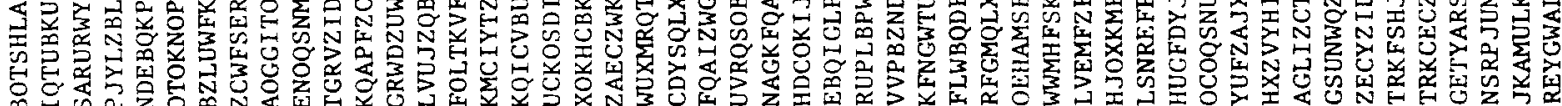

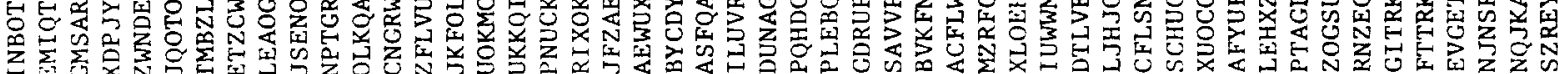

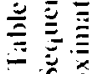

产玄

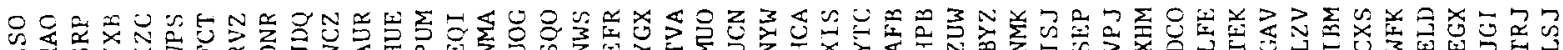

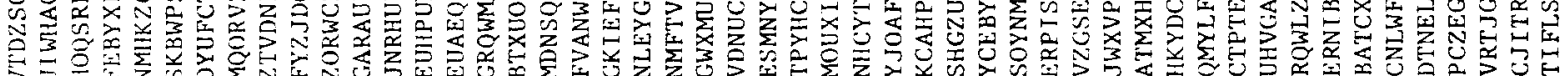

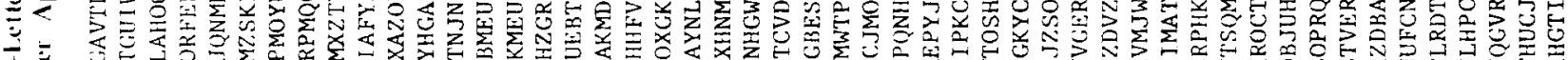

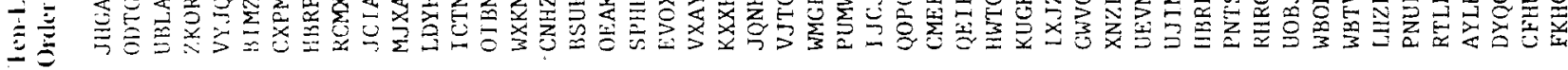


Table 6

Eight-Letter Sequences Without Repeated Letters

\begin{tabular}{|c|c|c|c|c|}
\hline o-order & Ist-order & 2nd-order & $3 \mathrm{rd}$-order & 4 th-order \\
\hline OKEBQ I HU & NUGLDEF I & KINLESCA & LEPICART & DINGLECT \\
\hline CVDHML IY & AYONUSGC & REAMPICO & DRACKETW & YOREDIUM \\
\hline HTCRDUN B & LHSNDTYU & ECLOSATH & CHISLAUC & LIMBERSO \\
\hline LRWDGFYV & AIOPHELK & KNDEYOSA & EPOICHAT & ARSHINKL \\
\hline PZQVKUGF & OKTAIUPS & EDSTHOUL & INYBETAL & DESPIRAL \\
\hline OMSBVPZQ & LEUNCOYA & WHE PLOBR & ENCHIM円. & YEDI TORY \\
\hline YLECVGWX & OAHRLEID & NTAROUL I & AVERSOMD & WILLDIERN \\
\hline ANARYOZW & ETCORSBH & ESHAKKIC & DERSEANY & CURTINeS \\
\hline VALRZTQC & DTUOHNAE & YECODSPR & MACE TWOL & FA匹EDSI \\
\hline NJKEMLDX & YUMADTRP & SITHORAN & EDSITHAL & SPFAL IHY \\
\hline UCQXSAWV & OBNMELDH & EMICHANS & MOUTSELY & POLICKI: [ \\
\hline HDFBKVJS & MLETDSHU & OUNGRSTH & NAMICHER & RINTOMUE: \\
\hline YUGKENSI & NDTCKUGM & ASOTHERM & CHOURNIS & PRAINSTE \\
\hline KWRF HVLJ & DPRAUBEO & IRSENYOC & HANITSEL & SURF INDO \\
\hline JMNROEBV & LHUAEOTG & DSEROUTH & STEMPORL & OMENTACK \\
\hline FKMI TPSC & NEGMFCUH & KASTYINE & ANSTRILIH & ONCESTIL \\
\hline AMOYSVQF & DSERWIK & ATHIBUNG & HEIRSTAN & APONSTER \\
\hline ERVSYCHW & UETDHCAM & ONSTLDAB & REASPICH & STANCEPT \\
\hline ZDXFCRKE & EDKRAQTV & THLASEWNG & ASYMBOLP' & ALICENTU \\
\hline EPXCMZRF & IFAODCKT & TALORGUC & ACKENIOM & HEMIINDOL \\
\hline MNUWHVLE & WAGTDBHE & HEDICKNC: & LOBTGER & REAIIONS \\
\hline$K Z B Q E M F$ & BWAENYRI & TUGLAPOF & GANDEOPL & MERIOUST \\
\hline NDZRISIK & IHENATUV & BUECADFT & BUASKENL & CLIMPANY \\
\hline WCR DT IBYY & ETF HRMLO & TNTHANED & SLABOURN & UMPERALS \\
\hline TQGPILND & HEPGIILA & OWAGUNER & OUPLYIND & LAPERSIN \\
\hline DUOGNATV & AUHTBROE & UNDECH LV & ALKINGFR & DICTORES \\
\hline HW PTFNCA & SNHETACY & LCAINDS & CAIFROVE & HAMBEDKO \\
\hline GFZCSOTQ & SOYWAGTF & DSPRAVEN & TRACH LNK & FAMI LEDS \\
\hline RKL POAEV & EOKABUSL & ATKNEDST & WORCALNC: & GLOBSERI \\
\hline F KMERJGC & GESBOAIN & SWHALIED & THEADISB & ONCERTAI \\
\hline HPFVXCKR & TSPEALNU & DOWACL IS & ORTSEACH & PENDLOTH \\
\hline URTMEVFA & NRTSGOWA & ELFRISAG & PLADINCE & EDICALMO \\
\hline CBINGSYJ & ICPEDTAB & WATH I PRE & DESTRUNG & BUILDENS \\
\hline HCZYSWUO & PNFROELT & MEBU I THA & ES PORNIC & PECIALSO \\
\hline EBU IWKMH & LRTNADEG & AIEROUNG & PERABOSI & TMPROBLE \\
\hline MWVHCBQ & KISDWFEN & HELARSWN & HANUDIES & CRYSTEMP \\
\hline IDVYENMK & RNYOTLHA & WACKNS PE & HERYINST & TOMINERS \\
\hline QTPZIFIV & DOIELMST & PSTHORID & STRIDEAC & BIOUSTYL \\
\hline JNUWHVGB & VNUIHETO & CINDASTH & INGETUCH & OMT NGERS \\
\hline EMFVDOXN & CTUDOLHR & OUGRIAASH & SEDOCKAG & REDUCKIN \\
\hline
\end{tabular}

\section{REFERENCES}

ATTNEAVE, F. Psychological probability as a function of experienced frequency. Joumal of Experimental Psychology $1953,46,81-86$.

BADDELEY, A. D. Immediate memory and the "perception" of letter sequences. Quarterly Journal of Experimental Psychology, 1964, 16, 364-367.

MAYZNER, M. S., \& TRESSELT, M. E. Tables of single-letter and diagram frequency counts for various word-length and letter-position combinations. Psychonomic Monograph Supplements, $1965,1(2$, Whole No. 2), 13-32.

MAYZNER, M. S., TRESSELT, M. E.. \& WOLIN, B. R. Tables of trigram frequency counts for various word-length and letter-position combinations. Psychonomic Monograph Supplements, 1965a, 1(3, Whole No. 3), 33-78.

MAYZNER, M. S., TRESSELT, M. E., \& WOLIN, B. R. Tables of tetragram frequency counts for various word-length and letter-position combinations. and letter-position combinations. 1965 b. 1(4, Whole No. 4), 79-143.

MERIKLE, P. M. Presentation rate and order of approximation to English as determinants of short-term mernory. Canadian Journal of Psychology, 1969, 23, 196-202.

MEWHORT, D. J. K. Familiarity of letter sequences, response uncertainty, and the tachistoscopic recognition experiment. Canadian Journal of Psychology, 1967. 21, 309-321.

MEWHORT, D. J. K., MERIKLE, P. M.. \& BRYDEN, $M$. $P$. On the transfer from iconic to short-term memory. Journal of Experimental Psychology, 1969, 81, 89-94.

MILLER, G. A., BRUNER, J. S.. \& POSTMAN, L. Familiarity of letter sequences and tachistoscopic identification. Joumal of General Psycbology, 1954, 50, 129-139.

MILLER, G. A., \& SELFRIDGE, J. A. Verbal context and the recall of meaningful material. American Joumal of Psychology, 1950, 63, 176-185.

SHANNON, C. E. A mathematical theory of communication. Bell System Technical Journal, 1948, 27, 379-423, 623-656.

SHANNON, C. E. Prediction and entropy of printed English. Bell System Technical Journal, 1951, 30, 50-64. 